\title{
A gestão da rede estadual de ensino da Paraíba por organizações sociais: tensões e desafios ${ }^{1}$
}

\author{
Educational management of the state of Paraíba by social \\ organizations: tensions and challenges
}

\section{La gestión de la enseñanza de la provincia de Paraíba por organizaciones sociales: tensiones y desafíos}

\author{
Ana Cláudia Cavalcanti de Araújo² \\ Universidade Federal da Paraíba, Doutoranda em Educação \\ http://orcid.org/0000-0002-4655-2404 \\ Felipe Baunilha Tomé de Lima ${ }^{3}$ \\ Universidade Federal da Paraíba, Doutorando em Educação \\ http://orcid.org/0000-0002-0317-9566 \\ Luiz Sousa Junior ${ }^{4}$ \\ Universidade Federal da Paraíba, Docente \\ https://orcid.org/0000-0002-5646-941X
}

Resumo: As mudanças na gestão pública, decorrentes em grande parte das transformações no padrão tecnológico, informacional, organizacional e gerencial acontecidas no mundo do trabalho, resultaram em novos métodos de administração dos sistemas educacionais em todo o mundo com base na chamada Nova Gestão Pública. Reformas educativas foram implementadas, com maior ou menor intensidade, em diferentes países, tendo como alvo a formação de sujeitos com novas habilidades e competências almejadas pelo mercado globalizado. No Brasil, a formulação, em 2004, de um marco legal das parcerias público-privadas foi decisiva para o surgimento de modelos de quase mercado, com repercussão nos sistemas educacionais. Para além da aceitação de padrões mercadológicos, as

\footnotetext{
Este artigo decorre da pesquisa: Análise do mapeamento das estratégias de privatização da educação básica no Brasil: atores, programas e consequências para a educação pública. Financiada pela Fapesp (Processo 2018/11340-0) e coordenada pela Prof. ${ }^{a}$ Dra. Theresa Adrião (Greppe/Unicamp), contou com a participação dos pesquisadores: Adriana Dragone Silveira (NUPE/UFPR), Cassia Domiciano (Greppe/UFMT), Elisangela Maria Pereira (Greppe/PMRC), Luiz de Sousa Junior (Grefin/UFPB), Marcia Cossetin (Greeppe/UFMT), Maria Augusta Peixoto (UFG), Maria Lúcia Ceccon (Greppe/Unicamp), Nadia Drabach (CEDES/ ISP-HTO), Raquel Borghi (GREPPE/Unesp), Regiane H. Bertagna (Greppe/Unesp), Sabrina Moehlecke (UFRJ), Selma B. Venco (Greppe/Unicamp) e Teise Garcia (Greppe/USP-RP).

2 Mestra em Ciências Econômicas pela Universidade Federal da Paraiba; Doutoranda em Educação pela Universidade Federal da Paraiba.

3 Mestre em Educação pela Universidade Federal do Rio de Janeiro; Doutorando em Educação pela Universidade Federal da Paraiba.

4 Doutor em Educação pela Universidade de São Paulo. Mestre em Educação pela Universidade Federal da Paraiba.
} 
reformas educativas impulsionaram a transferência da gestão educacional para o setor privado, seja por meio de instituições "pedagógicas" vinculadas a empresas privadas, seja por meio de Organizações Sociais (OS) constituídas com fins de gerenciamento dos bens públicos. No Estado da Paraíba, Nordeste do Brasil, todas as escolas da rede estadual tiveram sua gestão administrativa entregue a duas OS. Como se deu o processo de transferência da gestão administrativa dessas escolas e quais as implicações dessa mudança na gestão delas, particularmente na parte pedagógica? Este artigo, de caráter qualitativo, desenvolvido com base em pesquisa bibliográfica e documental, objetiva analisar a passagem da gestão das escolas estaduais para as Organizações Sociais. Intenta, ainda, perceber as mudanças nos processos de gestão pedagógica a partir das novas exigências constantes no contrato de gestão firmado com as OS e seus possíveis desdobramentos na organização escolar da rede estadual da Paraiba.

Palavras-chave: Nova Gestão Pública. Organizações Sociais. Rede estadual de ensino. Paraiba.

Abstract: Changes in public management, largely due to changes in the technological, informational, organizational and managerial pattern that have taken place in the world of work, have resulted in new methods of administering educational systems around the world based on the so-called New Public Management. Educational reforms have been implemented, to a greater or lesser extent, in different countries, targeting the formation of subjects with new skills and competences desired by the globalized market. In Brazil, the establishment, in 2004, of a legal framework for public private partnerships was decisive for the emergence of quasi-market models, with repercussions on educational systems. Beyond the acceptance of market standards, educational reforms boosted the transfer of educational management to the private sector, either through "pedagogical" institutions linked to private companies or Social Organizations (SO) established for the purpose of managing public goods. In Paraiba State, northeastern Brazil, all schools in the state network had their administrative management delivered to two SO. How was the process of transferring the administrative management of these schools and what are the implications of this change in school management, particularly in pedagogical management? This qualitative article, with bibliographic and documentary research, aims, therefore, to analyze the transition from the management of state schools to Social Organizations. It also intends to perceive the changes in the pedagogical management processes from the new requirements contained in the management contract signed with the OS and its possible consequences in the school organization of the state of Paraiba.

Keywords: New Public Management. Social organizations. State system of education. Paraiba.

Resumen: Los cambios en la gestión pública, en gran parte debido a los cambios en el patrón tecnológico, informativo, organizativo y administrativo que se han producido en el mundo del trabajo, han dado como resultado nuevos métodos de administración de sistemas educativos en todo el mundo basados en la llamada Nueva Gestión Pública. Las reformas educativas se han implementado, en mayor o menor medida, en diferentes países, dirigidas a la formación de sujetos con nuevas habilidades y competencias deseadas por el mercado globalizado. En Brasil, el establecimiento, en 2004, de un marco legal para las 
asociaciones público privadas (APP) fue decisivo para la aparición de modelos de cuasimercado, con repercusiones en los sistemas educativos. Más allá de la aceptación de los estándares del mercado, las reformas educativas impulsaron la transferencia de la gestión educativa al sector privado, ya sea a través de instituciones "pedagógicas" vinculadas a empresas privadas u Organizaciones Sociales (OS) establecidas con el propósito de administrar bienes públicos. En el estado de Paraiba, en el nordeste de Brasil, todas las escuelas de la red estatal todas las escuelas estatales tuvieron su gestión administrativa entregada a dos organizaciones sociales. ¿̇Cómo fue el proceso de transferencia de la gestión administrativa de estas escuelas y cuáles son las implicaciones de este cambio en la gestión escolar, particularmente en la gestión pedagógica? Por lo tanto, este artículo, de carácter cualitativo, con investigación bibliográfica y documental, tiene como objetivo analizar la transición de la gestión de las escuelas estatales para Organizaciones Sociales. También tiene la intención de percibir los cambios en los procesos de gestión pedagógica a partir de los nuevos requisitos contenidos en el contrato de gestión firmado con las organizaciones sociales y sus posibles consecuencias en la organización escolar de la red estatal de Paraiba.

Palabras clave: Nueva gestión pública. Organizaciones sociales. Red de educación estatal. Paraíba.

Recebido em 31 de outubro de 2019

Aceito em 5 de abril de 2020

Publicado em 28 de agosto de 2020

\section{INTRODUÇÃO}

As reformas educativas com foco na participação reduzida da esfera pública e, consequentemente, no fortalecimento do mercado passaram a ter proeminência a partir da crise enfrentada pelo capitalismo mundial, iniciada na década de 1970. Ela pode ser atribuída, de um lado, ao esgotamento das políticas econômicas de cunho keynesiano e do Estado de bem-estar social ${ }^{5}$ e, de outro, ao modelo de acumulação taylorista/fordista. ${ }^{6} 0$ modelo de organização do trabalho taylorista/fordista, que articulava a produção em massa, o parcelamento das tarefas, a introdução da esteira mecânica - que permitia um maior controle do ritmo de produção, a padronização das peças - e o pagamento de melhores salários,

5 As políticas econômicas defendidas pelo economista inglês John Maynard Keynes, grosso modo, preconizavam, em tempos de crise, a intervenção do Estado com vistas à criação de demanda efetiva e à retomada do crescimento econômico. Já o Estado do bem-estar social incorpora as políticas de proteção ao trabalho e de direitos sociais, incluindo educação, saúde, habitação, entre outros. Em ambas as vertentes, torna-se inevitável o crescimento do papel do Estado.

6 Taylorismo-fordismo, enquanto modelo de produção industrial, alia a padronização e a produção em série à intensificação do trabalho, por meio do chamado gerencialismo científico. 
os quais garantiam o consumo em massa, foi considerado extremamente rígido e, num certo ponto, ineficiente (MESK0, 2018).

Ademais, a partir da década de 1960, nesse cenário de incertezas, desponta a competição com a indústria japonesa e a crise do petróleo, as quais provocam mudanças na organização industrial, acelerando a saturação do modelo taylorista/fordista. Assim, um novo padrão de produção, denominado de toyotismo ou acumulação flexível - que reúne os instrumentos tecnológicos de comunicação e financeiros, com novas roupagens para a acumulação do capital - abre espaço à produção segmentada. Esse movimento intensificouse, fortemente, com o processo da globalização, abrangendo novos setores e regiões geográficas (HARVEY, 2014).

A chamada acumulação flexível, com o fito de tentar superar a rigidez do sistema taylorista/fordista e atender, de forma ágil, às necessidades do mercado, agora mais amplas e mais facilmente cambiáveis, "apoia-se na flexibilidade dos processos de trabalho, dos mercados de trabalho, dos produtos e padrões de consumo" e resulta no surgimento de setores de produção inteiramente novos, abertura de mercados e, sobretudo, em "taxas altamente intensificadas de inovação comercial, tecnológica e organizacional." (HARVEY, 2014, p. 140).

Para atender a essas novas exigências do mundo do trabalho, foram necessárias reformas educativas, implementadas, estas, com maior ou menor intensidade em diferentes países, tendo como alvo a formação de sujeitos com novas habilidades e competências demandadas pelo mercado globalizado. Assim, o ensino baseado em habilidades interpessoais "educa peças de engrenagem e enquadra-se no maquinário corporativo, de modo a garantir os lucros crescentes." (SPRING, 2018, p. 133). Essas reformas tiveram sua primeira onda de implementação nos anos de 1990, sob a supervisão de organismos internacionais, a exemplo do Banco Mundial e do Fundo Monetário Internacional. Contribuíram para o sucesso, ainda que de modo não definitivo, as transformações ocorridas tanto no padrão tecnológico e informacional quanto nos sistemas organizacional e gerencial no âmbito do mundo do trabalho, levando à introdução de novos métodos de administração dos sistemas educacionais em todo o mundo.

No Brasil, particularmente a partir de meados de 1990, foram soerguidos e disseminados aparatos jurídicos e políticas públicas que alavancaram as reformas educativas pró-mercado, destacando-se novos formatos de financiamento, políticas de avaliação externas e mudanças curriculares. 0 resultado foi um redesenho da atuação do poder público na educação, com redução da atuação do Estado, que permaneceu como financiador e avaliador das políticas sociais e de um conjunto de atividades ou serviços que permanece sob a tutela estatal e passa a ser gerido segundo a lógica de mercado (ADRIÃO; PERONI, 2009).

Este artigo, de natureza exploratória, de caráter bibliográfico e documental, fundamentado numa abordagem analítico-descritiva, apresenta a implantação de Parcerias 
Público-Privadas (PPP) na rede estadual de ensino da Paraíba, bem como os mecanismos da denominada Nova Gestão Pública, a partir da implantação de Organizações Sociais (OS) na rede, as quais passam a ser cogestoras das cerca de 650 escolas da rede estadual de ensino. 0 estudo teve como fontes primárias de dados a Lei Estadual n. 9.454 (PARÁ́BA, 2011) e o Edital de Seleção Pública n. 001/2017/SEAD/SEE (PARAíBA, 2017), relacionando-as com o referencial teórico utilizado e entrecruzando com elementos da conjuntura nacional e estadual.

\section{A CRISE DO ESTADO INTERUENCIONISTA E A NOUA GESTÃO PÚBLICA (NGP)}

Os anos dourados da economia capitalista, sob a égide do Estado do bem-estar social e das políticas econômicas de inspiração keynesiana erigidas pós-Segunda Guerra Mundial, duraram cerca de 30 anos. ${ }^{7}$ Contudo a crise econômica da década de 1970 e as garantias sociais consolidadas no modelo do Estado de bem-estar social tornaram-se fortes barreiras ao aumento da taxa de lucro das grandes corporações multinacionais.

Por outro lado, junto com a revolução tecnológica e informacional, a financeirização crescente do capitalismo incorpora-se como um elemento central para explicar a perda de força dos Estados nacionais na atuação em defesa de suas economias. As mudanças tecnológicas possibilitaram a automatização de boa parte da produção, gerando desemprego e um grande exército industrial de reserva, cuja força de trabalho está disponibilizada à venda a preços muito baixos e sem regulamentação. Somam-se a isso, ainda, a entrada das mulheres no mercado de trabalho e a invasão das novas tecnologias na vida privada, gerando trabalho não remunerado. A desregulamentação dos mercados de capitais e o fim do padrão ouro, estipulado no acordo de Breton Woods, constituíram a senha para a expansão desordenada do capital financeiro, que anteviu a oportunidade de se deslocar, em tempo real, para qualquer parte do mundo, especulando e trabalhando com as crises da economia real, quando não criadas artificialmente para lucro imediato em patamares nunca vistos até então.

Ademais, exigia-se que as atribuições do Estado fossem reduzidas e repassadas para o mercado, incluindo até mesmo as clássicas, como o poder de polícia e a segurança nacional. Naquelas funções em que a atuação do Estado fosse preservada, foi exigido, no

\footnotetext{
Os anos dourados, também conhecidos pelos "Trinta gloriosos", perduraram do final da Segunda Guerra Mundial, em meados de 1940, até o início dos anos de 1970. Nesse período, a economia capitalista experimentou crescimento econômico contínuo com redistribuição de renda, pelo menos nos países centrais. A crise do petróleo em 1973 inaugura uma nova fase de queda da produção e desestruturação econômica, resultando em perda da influência do ideário keynesiano. Um "novo" liberalismo se habilita como sucessor do Welfare State, com redução do papel do Estado, privatizações, cortes de gastos públicos e redução das poĺticas sociais.
} 
entanto, o compartilhamento das ações com o setor privado, sobretudo quanto à gestão. Essa imbricação entre público e privado na gestão dos bens públicos obnubila o próprio sentido de interesse coletivo, posto que os valores e a missão de um e de outro têm significações completamente distintas.

Assim, dois movimentos se articulam de forma combinada, no sentido de reconfigurar a gestão pública. Um primeiro movimento busca reduzir o alcance do Governo e a consequente introdução de novos atores, vindos do mundo dos negócios, na definição/ ação de políticas públicas. Já o segundo movimento diz respeito às alterações propugnadas no interior da própria administração pública, por meio do compartilhamento de modelos de decisões com base nos pressupostos mercantis, sob o argumento de modernização e eficiência da política governamental, nos mesmos moldes das empresas privadas, de modo a constituir o que veio a se denominar NGP (CÓSSI0, 2018).

A partir da década de 1990, a reforma do Estado no Brasil, e, posteriormente, de forma mais específica na esfera educacional, fundamenta-se num conjunto de medidas de inspiração neoliberal e neoconservadora (ADRIÃO; PERONI, 2005), visando adequar o País à competitividade internacional. Para acompanhar esse processo de redefinição do Estado, emerge um novo paradigma de administração pública, entendida como New Public Management (NPM); no Brasil, nomeada, por Pereira (1998), como modelo de administração pública gerencial ou Nova Gestão Pública (NGP). Esse movimento defende a implantação de princípios da lógica da iniciativa privada no setor público, uma tendência global em direção a um tipo de reforma administrativa, ocorrida nas décadas de 1980 e 1990:

abrigados sob o guarda-chuva da New Public Management (NPM), especialmente nos paises anglo-saxões, propunham soluções para a administração pública, cujos pontos centrais se referiam à adaptação e à transferência dos conhecimentos gerenciais desenvolvidos no setor privado para o público, pressupondo a redução do tamanho da máquina administrativa, uma ênfase crescente na competição e no aumento de sua eficiência. (PECl; PIERANTE; RODRIGUES, 2008, p. 41).

Organismos multilaterais, como $\circ$ Conselho Latino-Americano para o Desenvolvimento (1998), entendiam que, para a implantação da NPM, deveriam ser atendidas algumas particularidades, como: profissionalização da alta burocracia; transparência e responsabilização; descentralização na execução de serviços públicos; desconcentração organizacional nas atividades exclusivas do Estado; controle de resultados; novas formas de controles; agências que realizam atividades exclusivas do Estado e agências que atuam nos serviços sociais e científicos; orientação da prestação de serviços para o cidadão 
usuário e a modificação do papel da burocracia, no que se refere à democratização do poder público. Portanto, a NPM pode ser definida como um programa de reformas do setor público pautado em instrumentos da gestão privada, com o objetivo de melhorar tanto a eficiência quanto a eficácia dos serviços públicos nas modernas burocracias. Para alcançar esses pré-requisitos, os organismos públicos passaram a adotar métodos empresariais de gestão (management), com foco na eficiência, passando os servidores públicos a serem avaliados conforme critérios de desempenho, semelhantemente aos utilizados nas empresas privadas (COSTA, 2010; MOTTA, 2013).

0 NPM tem como objetivo primordial de fazer a Administração Pública operar como uma empresa privada e, assim, adquirir eficiência, reduzir custos e obter maior eficácia na prestação de serviços. Nesse sentido, a Administração Pública deveria apenas direcionar os serviços, e não executálos diretamente. Havia uma preferência por terceirizar e contratar fora. Por meio de vários provedores privados, poder-se-iam usar os benefícios da competição entre eles, evitando monopólios e permitindo maior flexibilidade na gestão. (MOTTA, 2013, p. 84).

As propostas da NPM foram implementadas inicialmente na Inglaterra, no Governo conservador de Margareth Thatcher, em 1979, e apoiadas nas ideias neoliberais de Hayek e Friedman. Costa (2010) ressalta que, a partir dos anos de 1960, alguns institutos já teciam críticas ao modelo de intervenção social democrata e defendiam um modelo baseado nas premissas do livre mercado e do neoliberalismo.

Em seguida, ainda de acordo com Costa (2010), os Estados Unidos da América, com a eleição de Ronald Reagan em 1980, adotaram, também, na administração pública, um modelo de gestão baseado nas empresas privadas, incorporando a proposta da NPM. A partir de 1984, foram implementados programas semelhantes em países como Austrália e Nova Zelândia, cujas reformas tiveram início em governos trabalhistas, sendo aprofundadas, posteriormente, em governos conservadores. Já na Inglaterra, a reforma gerencial iniciou no Governo conservador de Margareth Thatcher. Naquele país, as reformas foram assumidas, posteriormente, pelos trabalhistas, sob o comando de Tony Blair. Os trabalhistas, porém, viram na chamada terceira via um meio de justificar tais medidas:

o governo de Tony Blair persistiu com a mesma política de gestão adotada pelos conservadores, combinando economia de livre mercado, regulação estatal e terceirização de serviços sociais. Para sustentar ideológica e conceitualmente a deriva neoliberal do trabalhismo, Blair foi buscar na terceira via os argumentos de que precisava para eleger o mercado como força progressista. (COSTA, 2010, p. 150). 
As principais influências desse modelo foram extraídas das teorias da Escolha Racional ou Escolha Pública - Public Choice - e da Teoria do Agente Principal, sendo incorporados também aspectos contemporâneos da gestão empresarial, como: Total Quality Management (TQM), reengenharia, stakeholders, orientação a clientes, foco em resultados, flexibilização, remuneração variável por desempenho, etc. (MARINE, 2003).

A Public Choice, que tem como principal teórico James Buchanan, é resultado da escola de pensamento desenvolvida por economistas neoclássicos que adotaram o pressuposto do racionalismo econômico, no qual os indivíduos motivados apenas por benefício próprio tentam maximizar seus interesses econômicos. Trazendo esse conceito para o comportamento político na escolha dos indivíduos, Marine (2003) ressalta que esse racionalismo econômico pode ser observado quando os "eleitores votam de forma a atender aos seus interesses, políticos, visam à reeleição e burocratas procuram atender aos seus interesses corporativos." (MARINE, 2003, p. 48).

Com relação à Teoria do Agente Principal, entende-se que o pressuposto para sua existência são as relações contratuais na vida social, existindo a presença de dois agentes, em todas as transações: um, o contratante, identificado como principal, e outro, o contratado. Essa relação pode se apresentar de forma implícita ou explícita, e seu objetivo principal é alcançado quando se atinge a satisfação das partes, mesmo que essa satisfação seja dificultada pela assimetria de informações que, geralmente, vai favorecer uma das partes, o agente principal, por deter informação privilegiada (MARINE, 2003).

Assim, pautado nas teorias do Public Choice e do Agente Principal, o NPM tinha como ponto de partida uma análise econômica da política, no qual o setor público é examinado a partir do comportamento individual dos agentes que o integram, ou seja, o agente público possuía um maior espaço de atuação, fundamentado em mecanismos de controle gerencial mais efetivo (COSTA, 2010). Esse modelo gerencialista pode ser entendido, de maneira mais detalhada, a partir da abordagem de Abrucio (1997), que compara, quanto aos objetivos e sua relação com a sociedade, três correntes ou três fases do modelo da administração pública inglesa, classificando-as em: gerencialismo puro, consumenism e Public Service Orientation (PSO). Essa divisão é justificada pelo autor como uma maneira de facilitar a comparação entre elas. Ele ressalta:

há uma modificação substancial ao longo do tempo, do gerencialismo puro ao public service orientation. A constatação mais importante, no entanto, é que, embora haja diferenças entre as teorias, elas não são mutuamente excludentes. Ao contrário, o que se percebe é que há uma incorporação dos aspectos positivos de cada teoria. A passagem de uma teoria a outra é realizada através de uma crescente inclusão de temas. (ABRUCI0, 1997, p. 13). 
Na primeira fase, entende-se que o "ponto central do modelo gerencial puro é a busca pela redução de custos e o aumento da eficiência e produtividade da organização" (ABRUCI0, 1997, p. 11), ou seja, a redução de custos era o objetivo principal, o que estava de acordo com o ideário neoliberal, que buscava aproximar o setor público do eficiente e produtivo setor privado, ficando a máquina governamental condicionada a uma quantidade cada vez menor de atividades por ela executada, mesmo que à custa de forte redução dos serviços ofertados à maioria da população. Outro aspecto destacado nessa fase é a descentralização administrativa como uma importante opção organizacional capaz de aumentar a autonomia das agências e dos departamentos governamentais.

Já na segunda fase da teoria, o consumenism, a principal característica é a flexibilidade, empreendida pela gestão, da qualidade dos serviços públicos no atendimento às demandas do consumidor, o qual, a partir desse momento, passa a ter prioridades dentro do setor público. Essa flexibilização na gestão pública pode ser caracterizada pela transição da lógica do planejamento para a lógica da estratégia. Desse modo, ultrapassa-se o conceito de plano baseado em uma racionalidade técnica, em que se define apenas o melhor programa a ser seguido para um patamar em que são levadas em consideração as relações entre os atores envolvidos em cada política, o tipo de consumidor/cliente que demanda o serviço público e, sobretudo, a qualidade do serviço que será oferecido. Exige-se, portanto, um alto grau de mecanismos flexíveis de gestão, sendo necessárias eventuais alterações nos programas públicos, a fim de atender a cada tipo de demanda do consumidor (ABRUCI0, 1997).

Na terceira fase, que corresponde ao PSO, foram introduzidos os conceitos de accountability, transparência, participação e equidade na prestação dos serviços públicos. Esses conceitos eram entendidos como um mecanismo de responsabilização, no qual o governo local deveria incentivar a participação dos cidadãos nas decisões políticas, pois elas afetavam diretamente suas vidas.

os teóricos do PSO resgatam os ideais de participação política dentro de um conceito mais amplo, o de esfera pública, que se utiliza da transparência como proteção contra novas formas particularistas de intervenção na arena estatal, como o são o clientelismo e o corporativismo. Portanto, é a partir do conceito de esfera pública (public domain) que é estruturado o conjunto de idéias do Public Service Orientation (PSO). Esfera pública vista como local de aprendizagem social. Isto é, a esfera pública não é só o locus por excelência da participação dos cidadãos, mas sobretudo onde os cidadãos aprendem com o debate público. (ABRUCI0, 1997, p. 27).

Destarte, a transparência e o aprendizado social devem estar presentes também na organização interna da administração pública, principalmente no momento de elaboração 
das políticas públicas, quando a definição do planejamento estratégico deve ser levada ao debate público.

Como característica central desse modelo, temos a dispersão de poder, entendida, de acordo com Clarke e Newman (2012), como uma estratégia de reconstrução do Estado, em que há uma diminuição do papel deste e um alargamento de seu alcance na sociedade civil. Entretanto esses autores destacam que a redução, ou dispersão, do papel do Estado correspondeu à expansão do seu próprio poder, pois novos agentes não estatais passaram a ser considerados uma extensão dele. A partir desse momento, o Estado exercia um poder de regulação financeira, de contratação, de monitoramento e de vigilância.

Temos, assim, fases do modelo da administração pública. Contudo, segundo Abrucio (1997), não há uma utilização pura dessas fases, mas uma combinação entre elas, com tipos diferentes de arranjos. Como exemplo, temos a implantação do gerencialismo puro no País, que correspondeu à retração da máquina estatal, exigindo, para isso, o impulsionamento de alguns instrumentos gerenciais, como formas de racionalização orçamentária e controle orçamentário e técnico direcionadas para a avaliação do desempenho da atividade governamental.

Para que ocorra simplesmente a ampliação da dominação capitalista, a NPM defende não a retirada da participação do Estado, mas a sua reconstrução. "Passa-se da ideia de 'Estado Mínimo' para a de 'Estado Melhor', que também seria uma esfera regida pelas regras da concorrência e submetida às exigências de eficácia semelhantes às da empresa privada." (MARQUES; MENDES; MARANHÃ0, 2019, p. 352). Em meio a esse contexto, as propostas da NPM avançaram rapidamente, na tentativa de conter gastos e déficits públicos.

\footnotetext{
Promessas de reinvenção da Administração Pública eram bem-vindas pela população, pois trouxeram um novo otimismo na gestão pública por sucessivas idealizações de maior qualidade e eficiência. A crença em um mundo contemporâneo de mudanças rápidas e exigentes e novas soluções favorecia a proposição de inserção de práticas flexíveis de gestão privada no setor público. (M0TTA, 2013, p. 85).
}

Desse modo, fundamentado na racionalidade econômica, nos ideais do liberalismo clássico, na redução do tamanho do Estado e na inserção de instrumentos de mecanismos de mercado no governo, o espaço de intervenção estatal se reduzia às funções regulatórias, passando as políticas sociais a serem implementadas também por organizações da sociedade civil. Os cidadãos eram vistos como clientes, sendo os bens e os serviços públicos avaliados segundo critérios de mercado. A lógica do setor privado deve servir de referência também ao setor público. 
É neste contexto que a NGP se instaura como a possibilidade de refazer o contrato entre Estado e Sociedade, propondo maior envolvimento da comunidade. As parcerias aparecem como soluções que podem promover uma relação cooperativa entre o mundo dos negócios, as instâncias governamentais locais, os grupos de pais e o Estado. (POPKEWITZ, 2008 apud OLIVEIRA, 2005, p. 632-633).

A responsabilidade do Estado passou a ser questionada pelos defensores do livre mercado inclusive na área social, e especificamente na educação, em oposição à ideia defendida por autores como Robertson e Verger (2012) de que a educação deveria ser responsabilidade do Estado, "como atividade política e social complexa e que deve permanecer, em grande parte, se não totalmente, no setor público e a serviço de interesses públicos." (ROBERTSON; VERGER, 2012, p. १134).

A NPM foi sendo incorporada por importantes setores do Estado, mais especificamente na educação, até os dias atuais, o que justifica a grande quantidade de estudos sobre seus efeitos, contradições e dilemas (COSTA, 2010; MARQUES; MENDES; MARANHÃO, 2019; OLIVEIRA, 2015), "que, mesmo em face de significativas mudanças nos enfoques políticos a partir de 2003, ainda persiste contraditoriamente nas instituições e políticas públicas estatais." (OLIVEIRA, 2015, p. 635).

De acordo com os preceitos da NGP, para que se consiga promover e garantir uma educação de qualidade, faz-se necessário adotar uma política direcionada à avaliação da aprendizagem, de políticas, programas e ações. Constitui-se, dessa maneira, num poderoso mecanismo de regulação, pois esses indicadores nortearão o estabelecimento de metas de gestão, tendo um impacto direto sobre o financiamento da unidade escolar, em alguns casos influenciando também a remuneração dos docentes e, até mesmo, os currículos (OLIVEIRA, 2015). 0 que se espera desse movimento é a formulação de um indicador de qualidade do ensino que possa ser percebido pelo conjunto da sociedade e interferir na mobilização dos diferentes agentes escolares, de modo que suas práticas sejam ajustadas de acordo com os objetivos previamente estabelecidos, a fim de alcançar os resultados.

Essas políticas estão impregnadas de uma lógica consumista, em que o aluno ou pai de aluno, precisa permanentemente se orientar por indicadores de qualidade para fazer suas escolhas no "mercado educativo", mesmo quando não se trata de educação privada. E na realidade, essas pretensas políticas de responsabilização resultam em grande irresponsabilidade social, pois são incapazes de prever os riscos que impõem as gerações que se escolarizam e insensiveis com os que não conseguem responder aos critérios estabelecidos. (OLIVEIRA, 2015, p. 639-640). 
Nesse contexto, a NGP implementada no Brasil, formulada por Bresser Pereira e marcada pela lógica empresarial de mudanças nos modelos de produção, consumo e de mercado, teve como modelo a reforma realizada na Grã-Bretanha, conhecida como Managerialism. Esta tinha como pressupostos básicos o aumento da produtividade e a orientação ao consumidor. Ela foi defendida pelo então ministro Bresser Pereira, usando-se os seguintes argumentos: "a ideia geral é descentralizar, delegar autoridade. Mas é preciso ser específico, definir claramente os setores que o Estado opera, as competências e as modalidades de administração mais adequadas a cada setor." (PEREIRA, 1998, p. 32). A reforma do Estado abriu espaços para a constituição do que veio a se denominar Parcerias PúblicoPrivadas, as famosas PPPs.

\section{PÚBLICO NÃO ESTATAL E PARCERIAS PÚBLICO-PRIUADAS}

Na configuração de público não estatal, a natureza da propriedade é redefinida. De acordo com Adrião e Peroni (2009), a mudança ocorre mediante dois movimentos: por meio da alteração do status jurídico de uma instituição estatal, logo, pública, que passa a ser de direito privado, ou por meio da instituição de parcerias entre o Estado e as instituições privadas sem fins lucrativos, genericamente identificadas como integrantes do Terceiro Setor, para a execução das políticas sociais. Com as modificações ocorridas no cenário político e econômico no Brasil, a partir da década de 1990, a relação público-privado alcançou uma nova configuração no debate nacional, apresentando um novo formato na execução das políticas sociais, destacando-se medidas de instituição de um modelo de quase mercado educacional, por intermédio das chamadas Parcerias Público-Privadas.

Para Newman (2001 apud ROBERTSON; VERGER, 2012), as parcerias surgiram como um mecanismo para minimizar os danos causados por formas anteriores de privatização, ainda que sem abandoná-las, permitindo enquadramentos, interesses e objetivos múltiplos. 0 renascimento das parcerias estava ligado a mudanças ocorridas, de maneira mais ampla, em direção a uma terceira via. 0 novo modus operandi da privatização age, assim, como um mecanismo que permite o aproveitamento de valores, de cada parceiro, a serem capitalizados no futuro.

A transferência da responsabilidade da oferta das políticas sociais, especificamente das políticas educacionais, da esfera estatal para os setores privados é chamada, ideologicamente, de "parceria" entre o Estado e a sociedade civil, com o Estado contribuindo, financeira e legalmente, para propiciar a participação da sociedade civil (MONTAÑO, 2010). 
Em razão disso, as parcerias entre os setores público e privado passam a ser priorizadas pela legislação brasileira. A Emenda Constitucional n. 19, de junho de 1998, autorizou as mais variadas formas de parcerias e admitiu a destinação de recursos públicos para a esfera privada. A Lei Complementar n. 101, de maio de 2000, regulamentou a EC n. 19, estabelecendo normas para as finanças públicas voltadas para a responsabilidade na gestão fiscal. E, em 2004, a Lei n. 11.079 instituiu normas gerais para a licitação e a contratação de parceria público-privada no âmbito dos Poderes da União, dos estados, do Distrito Federal e dos municípios.

A partir de 2010, com a aprovação da Lei n. 12.349, as PPPs avançam em relação ao marco legal de 2004, tendo em vista novos dispositivos que dão preferência às tecnologias nacionais, na contratação dos serviços, com o intuito de gerar emprego e renda, e aos produtos e à tecnologia oriundos dos paises que compõem o Mercado Comum do Sul (MERCOSUL) (BRASIL, 2010).

Os Governos de Luiz Inácio Lula da Silva e de sua sucessora, Dilma Rousseff, intensificam investimentos em infraestrutura no País, por meio das PPPs, como forma de retomar o crescimento econômico após a debacle de 2009, em razão da crise internacional de 2008/2009. 0 Programa de Aceleração do Crescimento (PAC) foi uma das iniciativas desenvolvidas por esses Governos, com vultuosas cifras estatais executadas por meio de PPPs. A busca de parcerias com o setor privado sugere uma estratégia dos Governos Lula e Dilma de "coordenar" os mercados, "estabelecendo projetos com base nos recursos oriundos do mercado financeiro - especialmente dos fundos de pensão e do BNDES, via emissão de títulos públicos e por meio de investimentos diretos nas empresas." (JARDIM; SILVA, 2015, p. 54). Esse novo desenvolvimentismo, que provoca múltiplas interpretações, em nosso entendimento não implicou quebra da estrutura neoliberal de desenvolvimento em vigência no Brasil desde meados dos anos de 1990.

Cabe destacar que o padrão de investimento estatal do novo desenvolvimentismo foi interrompido com o Golpe Jurílico-parlamentar de 2016, que depôs a presidenta eleita Dilma Rousseff e fez ascender ao cargo maior do país o seu vice-presidente, Michel Temer. As medidas de austeridade fiscal apresentadas pelo novo governo e aprovadas pelo Congresso Nacional, em especial a Emenda Constitucional n. 95/2016 (BRASIL, 2016), diminuíram drasticamente a expectativa de investimento público em educação no Brasil. Soma-se a isso, também, a aprovação pelo Congresso da reforma trabalhista que possibilitou a ampliação da terceirização no serviço público (COSTA; DOMICIANO, 2020). 


\section{A IMPLEMENTAÇÃO DE ORGANIZAÇÕES SOCIAIS (OS) NA REDE ESTADUAL DE ENSINO DA PARAIIBA}

$\mathrm{Na}$ área educacional, Adrião (2017) enquadra em três dimensões as formas de operacionalizar a redução no modo de atuar do Estado nos diferentes contextos em que a educação básica está submetida. São elas: a privatização da oferta educacional, a privatização do currículo e a privatização da gestão da educação.

As PPPs são resultantes, portanto, do distanciamento do Estado da oferta direta da educação, mantendo seu foco no financiamento aos provedores (por meio de vales ou subsídios) e atuando na esfera da regulação e da avaliação dos serviços educacionais, o que contribuiu para a transformação do setor educacional, aumentando a autoridade dos atores privados envolvidos (ROBERTSON; VERGER, 2012).

As Leis n. 9.637/98 e n. 9.790/99 criaram a figura jurídica Organizações Sociais (OS) e Organizações da Sociedade Civil de Interesse Público (OSCIP). Estas foram, assim, habilitadas a estabelecer uma relação contratual com o Estado para a implementação e a gestão de políticas públicas e ações governamentais. Montaño (2010) chama atenção para a problemática de tais organizações - consideradas como integrantes da sociedade civil serem, ao mesmo tempo, tanto executoras quanto fiscalizadoras das políticas públicas.

Emerge dessa nova situação a possibilidade de uso dos seguintes mecanismos: o contrato de gestão e o termo de parceria. 0 contrato de gestão é considerado um dispositivo jurídico que inaugura a possibilidade de compromisso institucional entre o Estado e uma entidade pública estatal (agências executivas) ou uma entidade pública não estatal (organizações sociais). 0 contrato de gestão é uma maneira de o Estado transferir suas responsabilidades, por meio de $\mathrm{OS}$, sem estas, contudo, continuarem submetidas às exigências administrativas do poder público. Transferir a gestão de escolas e sistemas de ensino para o setor privado, como forma de ampliar o mercado educacional, é o objetivo das mudanças sugeridas, segundo Adrião (2013).

Na Paraíba, o contrato de gestão com OS foi implantado com base na Lei estadual n. 9.454, de outubro de 2011, que dispõe acerca da contratação de entidades para a gestão pactuada das ações e dos serviços de apoio escolar em unidades escolares da Secretaria de Estado da Educação. Por meio do Edital n. 001/2017/SEAD/SEE, que tem por objeto a "Seleção pública para seleção de organização social qualificada na área de educação visando a celebração de contrato de gestão pactuada para serviços de apoio nas unidades escolares da secretaria de estado da educação", o Governo estadual, por intermédio da Secretaria de Estado da Administração e da Secretaria de Estado da Educação, firmou contrato com duas Organizações Sociais com vistas a atuarem nas escolas estaduais da Paraíba. São elas: 
Espaço Cidadania e Oportunidades Sociais (ECOS), e Instituto Nacional de Pesquisa e Gestão em Saúde (INSAÚDE).

A ECOS, constituída em 19 de setembro de 1997, pessoa jurídica de direito privado, é uma associação sem fins lucrativos, com sede no Estado do Rio de Janeiro, e tem por finalidade promover a cidadania efetiva das pessoas, especialmente aquelas com deficiência, e dos grupos em situações de desvantagens sociais, mediante a capacitação de recursos humanos, de atividades esportivas, diversificadas em diferentes modalidades, promovendo a preparação, o treinamento e a geração de oportunidades de trabalho por meio da alocação e do agenciamento de postos de trabalho; a realização de seminários, congressos, cursos, ciclos de debates e pesquisa, publicação e atividades sociais, esportivas e culturais em geral, visando à plena integração desses cidadãos à sociedade; o desenvolvimento de ações científicas, ambientais, culturais, assessoria técnica, educacional, jurídica e outras com o mesmo fim, visando também à integração internacional. ${ }^{8}$

0 INSAÚDE, por sua vez, é uma instituição que obteve a qualificação como Organização Social, tendo como origem a construção do Hospital da Santa Casa Jesus Maria José, em agosto de 1948, preservada até hoje. Com sede em São Paulo, desenvolve ações e serviços nos Estados de São Paulo, Rio de Janeiro, Alagoas, Bahia e Paraíba, e tem como finalidade a atuação em todo o território nacional nas áreas de Assistência à Saúde e Serviços Médico-Hospitalares, Assistência Social e Assistência Social e Educacional.

Os primeiros contratos de gestão firmados pelo poder público com essas duas OS intentaram atuar nos seguintes campos da gestão escolar: vigilância, limpeza, portaria, educação especial, inspetoria, supervisão, orientação e psicologia. Vê-se, portanto, que os contratos não ficaram restritos à esfera administrativa das escolas, mas avançaram também sobre os campos pedagógicos, o que contraria a ementa do próprio Edital ou sugere o entendimento de que atividades de suporte pedagógico se constituem meramente em serviços de apoio às unidades escolares. Aqui, há de se esclarecer que a maioria da força de trabalho que atuava nas atividades-meio das escolas estaduais era composta de prestadores de serviços, isto é, pessoas com contratos precários, sem qualquer tipo de seleção pública ou concurso. Com a contratação das OS, esses trabalhadores foram "regularizados" perante a legislação trabalhista, tendo as carteiras de trabalho assinadas via Consolidação das Leis do Trabalho (CLT). ${ }^{9}$

De fato, o que à primeira vista ficou de fora dos contratos foi exclusivamente a atividade docente, esta, ao que tudo indica, entendida como atividade-fim de forma exclusiva. Esse entendimento denota uma incompreensão acerca do papel das demais atividades

Objetivos extraídos do Estatuto Social da ECOS.

Este, aliás, foi um dos principais argumentos utilizados pelo governo estadual para a aprovação das OS. 
pedagógicas de suporte ao ensino, sobretudo orientação e supervisão escolar, e uma releitura da própria Lei de Diretrizes e Bases da Educação Nacional (LDBEN), ${ }^{10}$ particularmente do Título VI, que trata dos "Profissionais da educação". No artigo 67, está previsto que os profissionais da educação terão acesso aos cargos públicos exclusivamente por meio de concurso de provas e títulos, seguindo o mesmo entendimento da Constituição Federal de 1988. A contratação desses profissionais pelas OS agride não somente a LDB, mas a própria Constituição Federal.

Para concretizar a gestão das ações e dos serviços de apoio escolar, a rede de ensino foi dividida em quatro grupos, com dois lotes cada, para fomentar a competição entre eles, totalizando oito lotes. Para a constituição desses lotes, foram selecionadas três dimensões correspondentes a: i) perfil da unidade escolar; ii) desempenho; e iii) infraestrutura do ensino ofertado. A cada dimensão correspondem algumas variáveis, conforme pode ser observado no quadro a seguir.

Quadro 1 - Dimensões e variáveis para a Gestão Pactuada com Organizações Sociais

\begin{tabular}{|c|c|}
\hline DIMENSÃO & VARIÁVEL \\
\hline \multirow{3}{*}{$\begin{array}{l}\text { Perfil da Unidade } \\
\text { Escolar }\end{array}$} & Quantidade de salas \\
\hline & Quantidade de alunos matriculados \\
\hline & Custeio \\
\hline \multirow{10}{*}{ Desempenho } & Média de proficiência do IDEPB do $1^{\circ}$ ano do Ensino Médio de 2016 \\
\hline & Média de proficiência do IDEPB do $3^{\circ}$ ano do Ensino Médio de 2016 \\
\hline & Média de proficiência do IDEPB, Anos Iniciais 2016 \\
\hline & Média de proficiência do IDEPB, Anos Finais 2016 \\
\hline & Taxa de Aprovação $1^{\circ}$ ano do Ensino Médio de 2015 \\
\hline & Taxa de Aprovação do $3^{\circ}$ ano do Ensino Médio de 2015 \\
\hline & Taxa de Aprovação do $5^{\circ}$ ano de 2015 \\
\hline & Taxa de Aprovação do $9^{\circ}$ ano de 2015 \\
\hline & Nota do IDEB, Anos Iniciais 2015 \\
\hline & Nota do IDEB, Anos Finais 2015 \\
\hline
\end{tabular}


A gestão da rede estadual de ensino...

\begin{tabular}{|l|l|}
\hline \multicolumn{1}{|c|}{ DIMENSÃO } & \multicolumn{1}{c|}{ VARIÁVEL } \\
\hline \multirow{5}{*}{ Infraestrutura } & Proporção de equipamentos adequados \\
\cline { 2 - 3 } & Sala de recursos multifuncionais para Atendimento Educacional Especializado (AEE) \\
\cline { 2 - 3 } & Refeitório \\
\cline { 2 - 3 } & Sala de Leitura \\
\cline { 2 - 3 } & Banheiro com acessibilidade \\
\cline { 2 - 3 } & Área verde \\
\cline { 2 - 3 } & Biblioteca \\
\cline { 2 - 3 } & Dependências e vias adequadas a alunos com deficiência ou mobilidade reduzida \\
\cline { 2 - 3 } & Laboratório de ciências \\
\cline { 2 - 3 } & Laboratório de informática \\
\cline { 2 - 3 } & Auditório \\
\cline { 2 - 3 } & Quadra de esportes \\
\hline & Pátio \\
\hline & Laboratório de Matemática e/ou Robótica \\
\hline
\end{tabular}

Fonte: Paraiba (2017).

0 critério para a escolha das variáveis, em cada dimensão, proporcionou que cada grupo captasse as características específicas das diferentes regiões da Paraíba, apresentando escolas semelhantes com características homogêneas em cada grupo e heterogêneas em relação aos outros grupos, garantindo o equillbrio e estimulando a competição administrada em cada grupo.

Os grupos foram formados de acordo com critérios específicos. Assim, cada lote tem características específicas, como matrículas, salas, servidores efetivos de apoio, IDEB, IDEPB, taxa de aprovação, taxa de abandono. Portanto, pode-se verificar uma concepção padronizadora de gestão das escolas a partir do contrato de gestão, com forte ênfase nos resultados dos exames externos, a exemplo do ĺndice de Desenvolvimento da Educação Básica (IDEB), associado ao Sistema Estadual de Avaliação da Paraíba (IDEPB), implementado em 2012 pelo Centro de Políticas Públicas e Avaliação da Educação (CAEd/UFJF)."

Assim, os sistemas de avaliação externos constituem um dos pilares da introdução das práticas gerencialistas na educação não apenas para aferir desempenho, como também para ampliar os espaços de competição entre escolas, docentes e alunos, visto que a rede

" Para consulta sobre o IDEPB, deve-se acessar o sítio eletrônico: 〈http://www.avaliacaoparaiba.caeduff.net/>. 
estadual de ensino da Paraiba desenvolve projetos específicos de premiação de docentes e alunos, com base num critério de meritocracia.

Por sua vez, os lotes foram agrupados em torno das Gerências Regionais de Educação (GREs), as quais correspondem à distribuição geoespacial das escolas estaduais. Segundo os contratos, os lotes foram assim estabelecidos: lote 1 e lote 2 - $1^{\circ}$ GRE; lote 3 e lote 4 $2^{a}$, $2^{a}$ e $14^{a}$ GREs; lote 5 e lote $6-3^{a}, 4^{a}$ e $5^{a}$ GREs; lote 7 e lote $8-6^{a}, 7^{a}, 8^{a}, 9^{a}, 10^{a}$, $11^{a}$ e $13^{a}$ GREs.

No que se refere ao desempenho das atribuições das OS, durante a vigência do Contrato de Gestão, será analisado o cumprimento de diversos objetivos, como suporte à educação inclusiva, ao professor, ao secretariado, suporte pedagógico e suporte de $\mathrm{Tl}$, acompanhamento pedagógico ao aluno, alimentação, limpeza, segurança, manutenção, gestão dos espaços pedagógicos, de estoques, de RH, prestação de contas e gestão financeira. A avaliação do cumprimento das metas do contrato de gestão será feita a partir de indicadores que remetem ao consumo pelos estudantes/clientes, como: Índice de Clima Escolar (ICE); Índice de Satisfação do Atendimento ao Público (IAP); Índice de Satisfação da Merenda Escolar (IME); Índice de Equilíbrio Financeiro (IEF); Índice de Suporte de TI; Índice de Segurança Escolar e Sistema Estadual de Avaliação da Educação da Paraíba - Avaliando IDEPB.

Novamente faz-se presente o modelo de monitoramento da gestão das OS por meio da avaliação externa, padronizada ao lado de outros indicadores, sobretudo aqueles que reconfiguram o status dos próprios alunos, os quais passam da condição de sujeitos aprendentes para a de clientes/consumidores, por meio da aferição dos índices de satisfação, numa espécie de Serviço de Atendimento ao Cliente (SAC) escolar.

A atuação das OS, por sua vez, será avaliada por ciclos de avaliação de natureza temporal - mensal, bimestral e anual - e que, ao final de cada ano, deve fornecer uma pontuação que resultará num conceito, o qual pode levar à renovação ou não do contrato e até mesmo à sugestão de desqualificação da OS, conforme se pode visualizar no Quadro 2.

Quadro 2 - Pontuação e conceito das OS e seus impactos

\begin{tabular}{|l|l|l|}
\hline \multicolumn{1}{|c|}{ PONTUAÇÃO } & \multicolumn{1}{c|}{ CONCETO } & \multicolumn{1}{c|}{ IMPACTO } \\
\hline 9,1 a 10 pontos & A - ÓTIMO & Aprovado - Sugestão de Renovação \\
\hline 8,1 a 9,0 pontos & B - MUITO BOM & Aprovado - Sugestão de Renovação \\
\hline 7,1 a 8,0 pontos & C - BOM & Aprovado - Sugestão de Renovação \\
\hline 5,1 a 7,0 pontos & D - SATISFATÓRIO & Aprovado - Passível de Renovação, após diagnóstico conjunto \\
\hline 4,1 a 5,0 pontos & E - RUIM & Reprovado - Não renova o Contrato \\
\hline$<4,0$ pontos & F - INSUFICIENTE & Reprovado - Não renova o Contrato Sugestão de Desqualificação \\
\hline
\end{tabular}

Fonte: Paraíba (2017). 
Na prática, as escolas estaduais passaram a ser geridas por essas instituições privadas, as quais terão que responder não apenas por metas administrativas, mas também por metas de desempenho (rendimento) escolar. A remuneração do corpo dirigente das OS terá uma parte fixa $(70 \%)$ e outra variável (até 30\%). 0 recebimento da parte variável decorrerá de cumprimento das metas esboçadas no plano de trabalho. Logo, as OS determinarão o "ritmo" da produção escolar - usando uma linguagem de mercado.

\subsection{A TRANSFERÊNCIA DE RECURSOS PÚBLICOS PARA AS OSS}

Umas das principais questões que envolvem a contratação de OS diz respeito à transferência de recursos públicos para o setor privado. Esse foi um dos temas centrais presentes nas disputas envolvendo as políticas educacionais dos anos de 1930 até os dias atuais. 0 fato, porém, é que as mudanças verificadas na legislação brasileira a respeito desse assunto sempre permitiram encontrar uma maneira de admitir brechas para essas transferências. 0 Quadro 3 mostra a estimativa de desembolso de verbas públicas da rede estadual de ensino para as duas OS.

Quadro 3 - Levantamento de desembolso estimado por lote

\begin{tabular}{|c|c|c|c|c|c|c|}
\hline Lotes & $\begin{array}{l}\text { Folha de } \\
\text { apoio } R \$\end{array}$ & $\begin{array}{l}\text { Manutenção } \\
\text { e pequenas } \\
\text { reformas R\$ }\end{array}$ & $\begin{array}{l}\text { Despesas } \\
\text { gerais } R \$\end{array}$ & $\begin{array}{c}\text { Total das } \\
\text { despesas R\$ }\end{array}$ & Matrículas & $\begin{array}{l}\text { Custo/ } \\
\text { aluno } R \$\end{array}$ \\
\hline Lote 1 & $1.048 .403,83$ & $108.164,48$ & $172.678,50$ & $1.329 .246,81$ & 46.168 & 28,79 \\
\hline Lote 2 & 1.128.769,20 & १२६.८२३,9९ & $202.467,36$ & $1.458 .060,55$ & 45.642 & 31,95 \\
\hline Lote 3 & $757.167,54$ & $67.659,69$ & $108.014,88$ & 932.842,11 & 28.245 & 33,03 \\
\hline Lote 4 & $697.617,59$ & $72.059,08$ & $115.038,27$ & $884.714,94$ & 28.608 & 30,93 \\
\hline Lote 5 & $1.000 .981,32$ & १३४.560,86 & 214.818,83 & $1.350 .361,01$ & 49.014 & 27,55 \\
\hline Lote 6 & $959.686,62$ & १२१.059,२६ & $193.264,30$ & $1.274 .010,18$ & 44.458 & 28,66 \\
\hline Lote 7 & $1.221 .937,70$ & १३1.981,90 & $210.701,68$ & $1.564 .621,28$ & 35.939 & 43,54 \\
\hline Lote 8 & 1.199.578,82 & १३३3.802,34 & 213.607,91 & $1.546 .989,07$ & 37.112 & 41,68 \\
\hline Total & 8.014.142,62 & 896.111,60 & $1.430 .591,73$ & $10.340 .845,95$ & 315.१८6 & 32,81 \\
\hline
\end{tabular}

Fonte: Paraiba (2017). 
Ao que tudo indica, esses valores estimados sofrerão reajustes ao longo dos anos. A assinatura do contrato estabelecido com a SEE visava desenvolver ações e serviços de apoio escolar em unidades escolares integrantes, especificadas no Edital n. 001/2017/SEAD/ SEE, para implantação e implementação de políticas administrativas no âmbito educacional nas unidades escolares. 0 contrato de gestão pactuada tem um prazo de vigência de 24 meses, contados a partir de sua outorga, podendo ser renovado.

Assim, com relação aos lotes 2, 4, 6 e 8, o valor contratualizado foi estimado em $R$ \$ 117.282.637,48. No $1^{\circ}$ mês, correspondia à quantia de $R \$ 7.203 .571,34$; nos $2^{\circ}, 3^{\circ}$ e $4^{\circ}$ meses, a $R \$$ 3.601.785,67; no $5^{\circ}$ mês, a R\$ 6.685.763,81; e, nos 18 meses subsequentes, à importância de $R$ \$ 5.143.774,74. Já com referência aos lotes 1, 3, 5 e 7, o contrato estabeleceu a importância global estimada em $R \$ 117.056 .294,64$. No $1^{\circ}$ mês, equivalia a $R \$ 7.171 .789,02$; nos $2^{\circ}$, $3^{\circ}$ e $4^{\circ}$ meses, a $\mathrm{R} \$$ 3.585.894,51; no $5^{\circ}$ mês, a $\mathrm{R} \$ 6.685 .377,15$; e, nos 18 meses subsequentes, ao valor de $\mathrm{R} \$$ 5.135.635,83. 0 somatório dos valores contratados perante as duas OS resulta, portanto, em $\mathrm{R} \$ 235.038 .932,12$. 0 valor médio por mês foi, portanto, de 9.793.289,84 para cada um dos 24 meses do contrato.

Considerando que, em 2017, as receitas do Fundeb ${ }^{12}$ da rede estadual da Paraíba foram de $\mathrm{R} \$ 922.887 .117,41$, multiplicando-se esse valor por dois - correspondente a 24 meses -, o gasto médio com o Fundeb resultaria em 12,73\% das receitas estimadas do Fundo. Esse valor deve corresponder, assim, ao segundo maior grupo de despesas, abaixo apenas das despesas relativas a pagamento aos profissionais da educação.

\section{TENSÕES E DESAFIOS DA IMPLANTAÇÃO DE OS NA PARAÍBA}

A implementação das OS na rede estadual de ensino do Estado da Paraíba não foi precedida de nenhum debate mais aprofundado acerca dos impactos dessa nova forma de gestão nas unidades escolares ou mesmo na qualidade do ensino. Tratou-se de uma decisão vertical da administração pública estadual, que já tinha adotado a mesma postura com relação a hospitais da rede pública, mas não na rede como um todo.

0 marketing usado para convencimento da opinião pública, e da própria comunidade escolar, atacou, em primeiro lugar, as relações de trabalho precarizadas de

12 0 Fundo de Manutenção e Desenvolvimento da Educação Básica e de Valorização dos Profissionais da Educação (Fundeb) corresponde à parcela de recursos vinculados à educação que são redistribuídos às redes estaduais e municiais de um estado, com base no número de matrículas multiplicado por um custo-aluno. Para o ano de 2017, a Paraíba recebeu o equivalente a $\mathrm{R} \$ 922.887 .117$, 41, segundo dados colhidos no Sistema de Informações sobre Orçamentos Públicos em Educação (SIOPE). 
um enorme contingente de "prestadores de serviços" da Secretaria de Educação do Estado, os quais eram contratados por tempo determinado, em geral correspondente ao ano letivo, sendo recontratados nos anos subsequentes. Com a introdução das OS, esse contingente de trabalhadores passou a ser contratado pela Consolidação das Leis do Trabalho (CLT), com direito, a partir de então, aos "benefícios" da CLT, como férias remuneradas, décimo terceiro etc., que, ironicamente, vêm sendo cortados, paulatinamente, com as reformas levadas a cabo nos Governos de Michel Temer e, agora, de Jair Bolsonaro. Por outro lado, esses trabalhadores saíram da folha de pagamento do Estado, abrindo folga para o cumprimento da Lei de Responsabilidade Fiscal, no que diz respeito ao dispositivo que regula o percentual máximo de gastos com pessoal com relação à receita corrente líquida. Contudo, ao serem contratados por uma entidade privada, esses trabalhadores passaram a submeter-se a uma mais rigorosa fiscalização e controle do trabalho realizado, sujeitos, portanto, à exploração maior de sua força de trabalho, além de cumprirem carga horária em escala diferente dos demais trabalhadores do quadro efetivo, isto é, os estatutários. Também ficaram mais pressionados ao cumprimento das metas estabelecidas nos contratos da OS com a Secretaria de Educação do Estado.

Um segundo elemento de análise quanto à presença das OS na gestão das escolas estaduais diz respeito ao fato de que a remuneração do seu corpo diretivo - conforme já se explicitou anteriormente - tem uma parcela variável decorrente do desempenho escolar, melhor dizendo, rendimento dos discentes em testes padronizados, o que levará, inevitavelmente, a que haja maior interferência da OS sobre o trabalho pedagógico das escolas, podendo resultar em conflitos quanto aos objetivos do Projeto Político-Pedagógico das escolas e aos interesse imediatos da OS e do seu corpo dirigente.

Avançando nessa análise, um terceiro ponto de tensão com relação às $O S$ se dá quando, ao adotarem um modelo de Serviço de Atendimento ao Cliente (SAC), essas organizações sociais sinalizam para um sistema híbrido de avaliação das escolas, mas sempre com foco no mercado educacional. De um lado, o desempenho dos estudantes em sistemas exógenos de avaliação estandardizados, mas, de outro, em um monitoramento regular das atividades escolares, por meio da "transformação" das famílias e dos próprios educandos em clientes da escola.

Esse modelo, portanto, vislumbra o produto da escola enquanto rendimento, fruto de avaliação externa e não do processo pedagógico propriamente dito. 0 monitoramento do desempenho dos "colaboradores" é terceirizado para a comunidade escolar, vista como consumidores do bem educacional e dos demais serviços de assistência, sem, contudo, realçar o papel do poder público no provimento dos "insumos" educacionais.

A adoção do contrato de gestão com OS na Paraiba se encontra ultimamente numa fase de incertezas, pois o Estado passa, desde dezembro de 2018, por uma investigação 
denominada Operação Calvário que investiga desvio de verbas de uma Organização Social atuante na área da saúde, especificamente no Hospital de Emergência e Trauma do Estado. Embora essas denúncias não tenham chegado, até o momento, à área de educação, há expectativas de que as investigações possam alcançar tais contratos. Nesse sentido, o Tribunal de Contas do Estado da Paraíba (TCE-PB) emitiu alerta de número 00382/19 à SEE, por conta de problemas detectados na transparência das informações obrigatórias, que deveriam ser disponibilizadas nos endereços eletrônicos das duas OS e no Portal da Transparência do Estado, o que prejudica o controle social e o processo de fiscalização por parte do próprio TCE-PB. 0 Tribunal também quer analisar os termos aditivos aos contratos originais que justifiquem valores excedentes pagos pelo Estado às duas $\mathrm{OS}$, os quais já atingem o montante de $R \$ 9.989 .393,50$, considerando-se apenas os dois primeiros meses do ano. 0 TCE justifica a emissão do alerta no sentido de, além de buscar prevenir fatos que comprometam resultados na gestão orçamentária, financeira e patrimonial, exigir do gestor atenção ao dever de fiscalizar o cumprimento de todas as disposições dos Contratos de Gestão, a fim de manter a probidade da Administração Pública. Em razão desse fato, em 2020, o governo estadual resolveu rescindir os contratos com as $0 S$ vinculadas à educação.

\section{CONSIDERAÇÕES FINAIS}

A relação público-privado, no contexto das políticas educacionais, reforçada pelas transformações ocorridas no mundo do trabalho e nas reformas da administração pública, iniciadas na década de 1990, ganhou novos desenhos e se concretizou em diversas formas de parcerias, destacando-se as Organizações Sociais. Essas inovações são orientadas pelos princípios da NGP. Boa parte dessas inovações foi implementada ou gestada já no primeiro ano do governo. Os critérios de avaliação passam a adotar a lógica de mercado na gestão pública, como sinônimo de eficiência, eficácia e aprimoramento. A oferta dos serviços públicos não foi transferida para organizações privadas, um indicativo de que a proposta do governo não era a de acabar com os sistemas públicos de saúde e educação. Prevaleceu a lógica da NGP, de terceirização dos serviços, sob o argumento de sua modernização. A transferência da gestão dos serviços públicos foi feita via contratos de gestão com OS. Esse contrato de gestão permitiu ao governo desafogar sua meta de pagamento de folha com pessoal, haja vista que o repasse de verbas é para pessoa jurídica (OS), que realiza o contrato de trabalho. Por outro lado, dificultou o controle social dos gastos públicos, uma vez que o controle agora é feito apenas pelo governo, abrindo margem para desvio de verbas públicas.

A adoção do contrato de gestão com Organizações Sociais na rede estadual da Paraíba ainda se encontra em seus primórdios e com resultados incertos. Chama a atenção a 
pouca transparência na execução dos contratos, sobretudo quanto ao repasse dos valores financeiros paras as duas 0 S, alcançando a cifra aproximada de 235 milhões de reais. Todavia já emergem, nos órgãos da imprensa, diversas denúncias sobre malversação dos recursos, o que levou o atual governo, eleito em 2018, a decretar novas regras para contratação de futuras $\mathrm{OS}$ e, por fim, rescindir os contratos.

São necessários novos estudos para averiguar o impacto da implantação desses mecanismos de gestão, em especial na educação e na gestão pedagógica das escolas. Houve melhora no desempenho das avaliações estandardizadas? Houve melhora na oferta de apoio e infraestrutura escolar?

A priori, pode-se destacar que, com a transferência da gestão do serviço de apoio e de uma parte do serviço pedagógico para as OS, o que temos é o desmonte da burocracia estatal e toda a base de dados e soluções construídas nas mãos de entes privados, uma espécie de "fuga de cérebros" da administração pública. Desse modo, as OS passam a conhecer mais a administração do sistema do que a própria burocracia estatal. Assim, em um certo período de tempo, abre-se a possibilidade concreta de perda de vista do caráter iminentemente público da educação e de transformação das escolas em empresas públicas de transmissão de conteúdo.

\section{REFERÊNCIAS}

ABRUCIO, F. L. 0 impacto do modelo gerencial na Administração Pública: um breve estudo sobre a experiência internacional recente. Cadernos ENAP, Brasília, DF, n. 10, 1997.

ADRIÃO, T. A privatização da educação básica no Brasil: considerações sobre a incidência de corporações na gestão da educação pública. In: ARAÚJO, L.; PINTO, J. M. R. (org.). Público x privado em tempos e crise. São Paulo: Fundação Lauro Campos e Fineduca, 2017. p. 16-37.

ADRIÃO, T. et al. A adoção de sistemas privados de ensino em escolas públicas de educação infantil: reflexões a partir do perfil dos professores. E-Curriculum, v. 11, n. 2, p. 434-460, 2013.

ADRIÃO, T.; PERONI, V. M. V. A educação pública e sua relação com o setor privado: implicações para a democracia educacional. Revista Retratos da Escola, Brasilia, DF, v. 3, n. 4, p. 107-116, jan./jun. 2009. Disponivel em: http//www.esforce.org.br. Acesso em: 29 out. 2019.

ADRIÃO, T.; PERONI, V. M. V. (org.). 0 público e o privado na educação: interfaces entre Estado e sociedade. São Paulo: Xamã, 2005. 
BRASIL. Emenda Constitucional n. 95, de 15 de dezembro de 2016. Altera o Ato das Disposições Constitucionais Transitórias, para instituir o Novo Regime Fiscal, e dá outras providências. Diário Oficial da União, Brasilia, DF, 15 dez. 2016. Disponível em: http://www.planalto.gov.br/ccivil_03/constituicao/ emendas/emc/emc95.htm. Acesso em: 29 out. 2019.

BRASIL. Lei n. 12.349, de 15 de dezembro de 2010. Altera as Leis nº 8.666, de 21 de junho de 1993, 8.958, de 20 de dezembro de 1994, e 10.973, de 2 de dezembro de 2004; e revoga o $§ 1$ do art. 2 - da Lei no 11.273, de 6 de fevereiro de 2006. Diário Oficial da União, Brasília, DF, 16 dez. 2010. Disponível em: http://www.planalto.gov.br/ccivil_03/_Ato2007-2010/2010/Lei/L12349.htm. Acesso em: 17 abr. 2020.

CENTRO LATINO-AMERICANO DE ADMINISTRAÇÃO PARA O DESENVOLVIMENTO. Uma nova gestão pública para a América Latina. 1998. Disponivel em: http:www.bresserwesite.org.br. Acesso em: 10 jul. 2019.

CLARKE, J.; NEWMAN, J. Gerencialismo. Educ. Real, Porto Alegre, v. 37, n. 2, p. 353-381, maio/ago. 2012.

CÓSSIO, M. F. A nova gestão pública: alguns impactos nas políticas educacionais e na formação de professores. Educação, Porto Alegre, v. 41, n. 1, p. 66-73, jan./abr. 2018.

COSTA, F. L. Reforma do Estado e contexto Brasileiro: crítica do paradigma gerencialista. Rio de Janeiro: Editora FGV, 2010.

COSTA, M. 0.; DOMICIANO, C. Austeridade fiscal, autoritarismo e política educacional: as mudanças legislativas na gestão democrática do sistema estadual de ensino e da escola pública de Mato Grosso. Educar em Revista, Curitiba, v. 36, e70086, 2020.

HARVEY, D. 0 neoliberalismo: história e implicações. São Paulo: Edições Loyola, 2014.

JARDIM, M. C.; SILVA, M. R. Programa de aceleração do crescimento (PAC): neodesenvolvimentismo? São Paulo: Ed. Unesp, 2015.

MARINE, C. Gestão Pública: o debate contemporâneo. Fundação Luís Eduardo Magalhães. Salvador: FLEM, 2003. (Cadernos FLEM, 7).

MARQUES, L. R.; MENDES, J. C. B.; MARANHÃO, I. M de L. A nova gestão pública no contexto da educação pernambucana e a qualidade organizacional. RBPAE, v. 35, n. 2, p. 351-367, maio/ago. 2019.

MESKO, A. de S. R. 0 programa "Educação - Compromisso São Paulo" e as estratégias de implementação das poĺticas empresariais na gestão escolar. 2018. 140 f. Dissertação (Mestrado em Educação) - Faculdade de Educação, Universidade Estadual de Campinas, Campinas, 2018.

MONTAÑO, C. Terceiro setor e questão social: crítica ao padrão emergente de intervenção estatal. 6. ed. São Paulo: Cortez, 2010.

MOTTA, P. R. M. 0 estado da arte da gestão pública. RAE-Revista de Administração de Empresas, v. 53, n. 1, p. 82-90, jan./fev. 2013. 
OLIVEIRA, D. A. Nova Gestão Pública e Governos Democrático-Populares: contradições entre a busca da eficiência e a ampliação do direito à educação. Educação e Sociedade, Campinas, v. 36, n. 132, p. 625-646, jul./set. 2015.

OLIVEIRA, R. Empresariado industrial e educação brasileira: qualificar para competir? São Paulo: Cortez, 2005. (Coleção Questões de nossa Época, 124).

PARÁBA. Edital de seleção n. 001, de 1 de julho de 2017. Seleção pública para seleção de organização social qualificada na área de educação visando à celebração de contrato de gestão pactuada para serviços de apoio nas unidades escolares da Secretaria de Estado da Educação. Diário Oficial do Estado da Paraíba, João Pessoa, 1 jul. 2017. Disponível em: http://static.paraiba.pb.gov.br/2017/07/ EDITAL_OS-final.pdf . Acesso em: 16 abr. 2020.

PARÁ́BA. Lei n. 9.454, de 6 de outubro de 2011. Institui o programa de gestão pactuada, dispõe sobre a qualificação de Organizações Sociais e dá outras providências. Diário Oficial do Estado da Paraíba, João Pessoa, 6 out. 2011. Disponível em: https://paraiba.pb.gov.br/diretas/secretaria-da-saude/arquivos-1/legislacao/lei-9454.pdf. Acesso em: 16 abr. 2020.

PECl, A.; PIERANTE, O. P.; RODRIGUES, S. Governança e New Public Management: Convergências e contradições no contexto brasileiro. 0\&S., v. 15, n. 46, jul./set. 2008.

PEREIRA, L. C. B. A reforma do Estado dos anos 90: lógica e mecanismos de controle. Brasilia, DF: Ministério da Administração Federal e Reforma do Estado, 1998.

ROBERTSON, S.; VERGER, A. A origem das parcerias público-privadas na governança global da educação. Educação e Sociedade, Campinas, v. 33, n. 121, p. 1133-1156, out./dez. 2012.

SPRING, J. Como as corporações globais querem usar as escolas para moldar o homem para o mercado. Campinas: Vide Editorial, 2018.

Endereços para correspondência: Rua José Clementino de Oliveira, 120, 58042-300, Tambauzinho, João Pessoa, Paraiba, Brasil; luizsjunior@gmail.com

Roteiro, Joaçaba, u. 45, p. 1-26, jan./dez. 2020 | e23370 |E-ISSN 2177-6059 
